\title{
Produtividade de soja e milho após coberturas de inverno e descompactação mecânica do solo
}

\author{
Henrique Debiasi( ${ }^{(1)}$, Renato Levien(2), Carlos Ricardo Trein ${ }^{(2)}$, Osmar Conte ${ }^{(2)}$ \\ e Karina Marie Kamimura(2)
}

\begin{abstract}
(1)Embrapa Soja, Rodovia Carlos João Strass, Distrito da Warta, Caixa Postal 231, CEP $86001-970$ Londrina, PR. E-mail: debiasi@cnpso.embrapa.br (2)Universidade Federal do Rio Grande do Sul, Faculdade de Agronomia, Departamento de Solos, Avenida Bento Gonçalves, 7.712, CEP 91540-970 Porto Alegre, RS. E-mail: renatole@ufrgs.br, trein@ufrgs.br, agriconte@gmail.com, karinamarie.kamimura@gmail.com
\end{abstract}

Resumo - O objetivo deste trabalho foi avaliar o efeito de coberturas de inverno e da descompactação mecânica do solo sobre o desempenho de soja e milho, em sistema de plantio direto. Foram conduzidos dois experimentos em Eldorado do Sul, RS, sobre Argissolo Vermelho compactado, nas safras 2005/2006 e 2006/2007. No primeiro, o delineamento experimental foi em blocos ao acaso, com parcelas subdivididas. Os tratamentos consistiram de duas profundidades teóricas de atuação da haste sulcadora da semeadora $(0,06$ e $0,12 \mathrm{~m}$, subparcela) e de três tipos de coberturas do solo no inverno (parcela): pousio, aveia-preta (Avena strigosa) e aveia-preta+ervilhaca (Vicia Sativa). Em 2006, a cobertura aveia-preta+ervilhaca foi substituída por nabo-forrageiro (Raphanus sativus). No segundo experimento, realizado em blocos ao acaso, o solo foi escarificado e os tratamentos consistiram do uso de aveia-preta ou nabo-forrageiro como cobertura de inverno. Os cultivos de cobertura reduziram a compactação superficial do solo (0-0,06 m) em comparação ao pousio e, na safra 2006/2007, sob condições de baixa disponibilidade hídrica, proporcionaram maior produtividade de milho e soja. Isso não se repetiu em 2006/2007, quando a disponibilidade hídrica foi adequada. O aumento da profundidade de atuação das hastes sulcadoras não influenciou a produtividade da soja e do milho. A escarificação reduziu a produtividade da soja e do milho em relação ao SPD contínuo.

Termos para indexação: Glycine max, Zea mays, escarificação, plantas de cobertura, sistema de plantio direto.

\section{Soybean and corn yield after soil winter covers and soil mechanical loosening}

\begin{abstract}
The objective of this work was to evaluate the effect of soil winter covers and soil mechanical loosening on soybean and corn yield, in no-tillage system. Two experiments were carried oud in Rio Grande do Sul state, Brazil, in a compacted Argissolo Vermelho (Haplic Acrisol), in the 2005/2006 and 2006/2007 crop seasons. The first experiment was carried out in a complete block design, with a split plot arrangement. The treatments were two theoretical working depths of a driller chisel-type furrow opener $(0.06$ and $0.12 \mathrm{~m}$, split plot), and three soil winter covers (main plot): fallow, black oat (Avena strigosa), and black oat+common vetch (Vicia sativa). In 2006, the soil cover black oat+common vetch was replaced by oilseed radish (Raphanus sativus). In the second experiment, in a complete block design, the soil was chiseled and treatments consisted of black oat or oilseed radish as winter cover crops. Cover crops reduced soil superficial $(0-0,06 \mathrm{~m})$ compaction compared to fallow and, in the 2005/2006-crop season, under low water availability, provided higher soybean and corn yields. In the 2006/2007-crop season, when water availability was higher, the same did not happen. Increasing working depths of the chisel-type furrow opener did not affect soybean or corn yields. Soil chiseling reduced soybean and corn yields in comparison to the continuous no-tillage system.
\end{abstract}

Index terms: Glycine max, Zea mays, chiseling, cover crops, no-tillage system.

\section{Introdução}

A compactação do solo é uma importante causa de perdas na produtividade da soja e milho, em razão de modificações físicas no ambiente radicular. Essas alterações englobam a redução da disponibilidade de oxigênio e água e o aumento da resistência do solo ao crescimento radicular (Cavalieri et al., 2006), o que limita a profundidade e o volume de solo explorado pelas raízes. Assim, os efeitos da compactação sobre a produtividade das culturas são mais evidentes sob condições de excesso ou deficit hídrico (Beutler et al., 2005).

Em sistema plantio direto (SPD), a escarificação tem sido indicada como opção para o rompimento de camadas compactadas de solo (Klein \& Camara, 
2007). Porém, os efeitos da escarificação normalmente persistem por curto período, igual ou inferior a um ano (Reichert et al., 2009). Além disso, a escarificação nem sempre favorece aumentos na produtividade (Klein \& Camara, 2007), especialmente em solos de textura arenosa a média (Lima et al., 2006), em que o grau de compactação crítico é mais elevado (Reichert et al., 2003).

Assim, outras medidas de manejo da compactação vêm sendo recomendadas, como o uso de plantas de cobertura, com elevada produção de fitomassa e sistema radicular abundante, capazes de romper camadas compactadas e produzir bioporos, através dos quais as raízes das culturas podem se desenvolver (Silva \& Rosolem, 2002). Ao contrário dos poros produzidos pela mobilização mecânica, os bioporos são longos e contínuos, efetivos na condução de água e ar (Oades, 1993). Além disso, os resíduos das plantas de cobertura colaboram para a manutenção de maiores conteúdos de água na superfície do solo (Andrade, 2008), diminuem os efeitos da compactação e promovem a ciclagem de nutrientes. Contudo, ainda persistem dúvidas quanto à eficiência dessa prática, principalmente no que se refere à produtividade das culturas.

$\mathrm{O}$ aumento da profundidade de atuação das hastes sulcadoras das semeadoras-adubadoras, ao romper de forma localizada camadas compactadas em superfície (Conte et al., 2009), é uma medida que também pode estimular o desenvolvimento radicular e reduzir os efeitos da compactação sobre a produtividade da soja e do milho, enquanto a recuperação física por processos biológicos está em andamento.

O objetivo deste trabalho foi avaliar o efeito de coberturas de inverno e da descompactação mecânica do solo sobre o desempenho de soja e milho, em plantio direto.

\section{Material e Métodos}

O experimento foi implantado em junho de 2002, na Estação Experimental Agronômica, da Universidade Federal do Rio Grande do Sul, em Eldorado do Sul, RS $\left(30^{\circ} 05^{\prime} \mathrm{S}\right.$ e $\left.51^{\circ} 40^{\prime} \mathrm{W}\right)$, sobre Argissolo Vermelho distrófico típico, franco-argilo-arenoso (513, $218 \mathrm{e}$ $269 \mathrm{~g} \mathrm{~kg}^{-1}$ de areia, silte e argila, respectivamente). O clima é do tipo Cfa (subtropical úmido), pela classificação de Köppen. A área experimental constituía-se, originalmente, de um campo natural pastejado por bovinos, sob alta carga animal, o que resultou na degradação física da camada superficial do solo. Essa afirmação é comprovada pela elevada densidade do solo e pelos baixos valores de porosidade total, macroporosidade e microporosidade na camada de $0,0-0,12 \mathrm{~m}: 1,71 \mathrm{Mg} \mathrm{m}^{-3}, 0,35,0,06$ e $0,29 \mathrm{~m}^{3} \mathrm{~m}^{-3}$, respectivamente. $\mathrm{O}$ valor de densidade do solo era superior ao limite crítico para o desenvolvimento das plantas sugerido por Reichert et al. (2003), que corresponde à faixa entre $1,40 \mathrm{e} 1,50 \mathrm{Mg} \mathrm{m}^{-3}$ para solos de textura similar ao utilizado neste trabalho. Da mesma forma, o volume de macroporos era inferior a $0,10 \mathrm{~m}^{3} \mathrm{~m}^{-3}$, valor este considerado por $\mathrm{Xu}$ et al. (1992) como o mínimo necessário para garantir uma adequada difusão de oxigênio às raízes.

Foram realizados dois experimentos. No primeiro, o delineamento experimental foi em blocos ao acaso, com parcelas subdivididas e quatro repetições. Os tratamentos principais, dispostos nas parcelas $(5 \times 20 \mathrm{~m})$, consistiram de três coberturas de inverno: pousio, aveia-preta (Avena strigosa Schreb) e o consórcio aveia-preta+ervilhaca (Vicia sativa L.). Os tratamentos secundários, alocados nas subparcelas $(2,5 \times 20 \mathrm{~m})$, englobaram duas profundidades de atuação da haste sulcadora de adubo, durante a semeadura das culturas de verão: $0,06 \mathrm{~m}$ (raso) e $0,12 \mathrm{~m}$ (profundo). Em 2006, a aveia-preta+ervilhaca foi substituída por nabo-forrageiro (Raphanus sativus L.). Cada cobertura de inverno ocupou duas parcelas num mesmo bloco, de forma que, no verão, numa delas foi semeado o milho e, na outra, a soja, em rotação anual. No inverno, cada cobertura foi semeada sobre a mesma parcela principal. Todos os tratamentos foram conduzidos em SPD.

O segundo experimento foi conduzido em blocos ao acaso, com dois tratamentos e três repetições. Em maio de 2006, uma área adjacente ao primeiro experimento foi escarificada na profundidade média de $0,25 \mathrm{~m}$, sem gradagem subsequente. De 2002 a 2005, essa área havia sido conduzida sob SPD e ocupada por soja e milho no verão, em rotação anual, e pousio no inverno, com práticas de manejo idênticas às usadas no experimento. Após a escarificação, essa área foi dividida em três blocos, compostos por duas parcelas $(5 \times 20 \mathrm{~m})$, cultivadas com aveia-preta ou nabo-forrageiro. A soja e o milho foram semeados com as hastes sulcadoras reguladas para atuar à profundidade de $0,06 \mathrm{~m}$.

A semeadura das plantas de cobertura, do milho e da soja foi executada por meio de uma 
semeadora-adubadora tratorizada. A colheita da soja e do milho também foi mecanizada, mediante o uso de uma colhedora autopropelida de grãos. O tráfego de máquinas relacionado à pulverização e aplicação de fertilizantes foi realizado na área entre as parcelas. As demais operações mecanizadas foram realizadas sob tráfego controlado, ou seja, a passagem dos rodados do trator e da colhedora ocorreu sempre nas mesmas regiões dentro das parcelas.

Para este trabalho, foram considerados os dados obtidos nas safras de 2005/2006 e 2006/2007. Nessas safras, a semeadura das coberturas de inverno foi realizada no mês de junho, sem adubação de base. As quantidades de sementes puras viáveis empregadas foram de $60 \mathrm{~kg} \mathrm{ha}^{-1}$ de aveia-preta, $8 \mathrm{~kg} \mathrm{ha}^{-1}$ de nabo-forrageiro e 45 e $25 \mathrm{~kg} \mathrm{ha}^{-1}$ para o consórcio aveia-preta+ervilhaca, com espaçamento de $0,17 \mathrm{~m}$ entre linhas. Em todas as safras e coberturas de inverno, à exceção do pousio, aplicaram-se $50 \mathrm{~kg} \mathrm{ha}^{-1}$ de ureia, aos 30 dias após a semeadura. As coberturas de inverno foram manejadas com duas dessecações, uma em outubro e outra no início de dezembro, tendose empregado o herbicida glifosato. A soja e o milho foram semeados sempre no primeiro decêndio de dezembro, à profundidade de $0,05 \mathrm{~m}$. A quantidade de sementes utilizada foi suficiente para a obtenção de uma população de 400 mil plantas por hectare, para a cultivar de soja BRS 154, e de 65 mil plantas por hectare, para os milhos híbridos D 766, em 2005/2006, e P 3069 , em 2006/2007, em espaçamento de 0,45 e $0,90 \mathrm{~m}$, respectivamente. As sementes de soja receberam inoculação de Brayrhizobium japonicum. A adubação de base foi executada de acordo com a análise de solo e conforme as recomendações da Comissão de Química e Fertilidade do Solo (Sociedade Brasileira de Ciência do Solo, 2004). A adubação nitrogenada de cobertura no milho foi realizada no estádio V6, com aplicação de ureia, em dosagem apropriada para a produtividade de $7 \mathrm{Mg} \mathrm{ha}^{-1}$ de grãos, tendo-se considerado uma gramínea como cultura antecedente. Os demais tratos culturais seguiram as recomendações da pesquisa para as culturas na região.

A produtividade da soja foi estimada por meio da coleta das plantas existentes em $12 \mathrm{~m}$, das três fileiras centrais de cada subparcela. Para o milho, colheu-se, de cada subparcela, uma amostra das plantas existentes em $12 \mathrm{~m}$ da fileira central. Os valores de produtividade foram corrigidos para a umidade de 13\%. Para a determinação dos componentes de produção da soja (número de legumes por planta e de grãos por legume, além da massa de mil grãos), foram amostradas 10 plantas por subparcela. Para o milho, contou-se o número de espigas em $12 \mathrm{~m}$ da fileira central. Após a trilha, para determinação da produtividade, foram separados 500 grãos por amostra, o que possibilitou a determinação da massa de mil grãos e da massa média de cada um deles (umidade de 13\%). Tendo-se dividido a massa de grãos por metro quadrado, obtida na estimativa da produtividade, pela massa de cada um deles e pelo número de espigas por metro quadrado, obteve-se o número de grãos por espiga. A população de plantas foi determinada na colheita, mediante contagem das plantas existentes em quatro metros de fileira, em dois locais por subparcela. Determinou-se, ainda, a quantidade de palha na superfície do solo no momento da semeadura da soja e do milho, pela coleta e secagem em estufa $\left(65^{\circ} \mathrm{C}\right)$ do material contido em uma área de 0,6x0,4 m.

Amostras indeformadas de solo foram coletadas em junho (experimento sob SPD contínuo) e em novembro (área escarificada) de 2006, nas camadas de 0,030,06 e $0,12-0,15 \mathrm{~m}$, por meio de anéis de $0,06 \mathrm{~m}$ de diâmetro e $0,025 \mathrm{~m}$ de altura, para a determinação de densidade do solo, porosidade total, macroporosidade e microporosidade, conforme Claessen et al. (1997). Em cada tratamento, coletaram-se dois anéis por profundidade e por repetição. Em junho de 2006, foi coletada uma amostra deformada de solo, de cada um dos tratamentos conduzidos na área escarificada e sob SPD contínuo, composta por 40 subamostras extraídas da camada de $0,00-0,12 \mathrm{~m}$ de profundidade, para análise do $\mathrm{pH}$ em água, da capacidade de troca catiônica, da saturação por bases e dos teores de $\mathrm{P}, \mathrm{K}$, $\mathrm{Al}, \mathrm{Ca}$ e Mg. Para a determinação do teor de matéria orgânica do solo (MOS), coletou-se uma amostra de solo por tratamento e por repetição, da camada de 0,00 $0,12 \mathrm{~m}$, cada uma composta por cinco subamostras. Todas as análises químicas foram efetuadas conforme Tedesco et al. (1995).

Os dados de cada experimento foram submetidos à análise da variância, a $5 \%$ de probabilidade, em separado. A resposta de variáveis de solo e planta a sistemas de rotação de culturas é de pequena magnitude e ocorre de médio a longo prazo. Assim, optou-se por comparar as médias dos tratamentos por meio do teste de Duncan, a 5\% de probabilidade, que se constitui em 
um teste menos rigoroso. AANOVA e o teste de Duncan foram realizados por meio do programa SOC-Embrapa. Para comparar a produtividade e os componentes da produção da soja e do milho medidos na área sob SPD contínuo com os medidos na área escarificada, foi empregado o teste $\mathrm{t}$ de Student, bilateral para dados não pareados, a 5\% de probabilidade, efetuado com programa Microsoft Excel. Optou-se pelo teste $\mathrm{t}$ em razão de que as áreas escarificadas e sob SPD contínuo se constituírem de experimentos separados, que ocupavam parcelas que não foram mutuamente casualizadas. Assim, como a independência dos erros, uma das pressuposições da ANOVA não foi atendida, essa análise não pôde ser realizada.

\section{Resultados e Discussão}

As profundidades teóricas de trabalho resultaram nas seguintes profundidades efetivas: $0,054 \mathrm{~m}$ (raso) e 0,084 m (profundo), em 2005/2006; e 0,116 m (raso) e $0,146 \mathrm{~m}$ (profundo), em 2006/2007. Na safra 2005/2006, a produtividade da soja e do milho foi significativamente maior nos tratamentos aveia-preta e aveia-preta+ervilhaca, em comparação ao pousio, em ambas as profundidades de atuação das hastes (Tabela 1). Esse comportamento não se repetiu em $2006 / 2007$, em que as coberturas de inverno não influenciaram a produtividade de ambas as culturas. Nas duas safras, a profundidade da haste sulcadora não teve efeito sobre a produtividade do milho e da soja. Mesmo com a melhor distribuição de chuvas na safra 2006/2007 (Figura 1 B), a produtividade média do milho nessa safra foi $29 \%$ inferior à obtida em 2005/2006, quando o período reprodutivo da cultura coincidiu com uma forte deficiência hídrica (Figura $1 \mathrm{~A}$ ). Esse comportamento pode ser explicado pelo ataque da lagarta-do-cartucho (Spodoptera frugiperda) na safra 2006/2007. Mesmo com três aplicações de inseticidas, na fase inicial de desenvolvimento da cultura, essa praga não foi controlada de forma satisfatória, o que resultou em perdas na produtividade do milho.

À exceção do teor de MOS, as diferenças nos atributos químicos de solo na camada de 0,00-0,12 $\mathrm{m}$, em consequência das coberturas de inverno, não foram significativas (Tabela 2). Assim, a maior produtividade da soja e do milho, nos tratamentos aveia-preta e aveia-preta+ervilhaca, na safra 2005/2006, provavelmente esteve relacionada ao menor grau de compactação na superfície do solo (Tabela 3) e a uma possível redução nas perdas de água do solo pela cobertura morta. A aveia-preta e o consórcio aveia-preta+ervilhaca apresentaram os menores valores de densidade do solo e os maiores de porosidade total e macroporosidade, na camada de $0,03-0,06 \mathrm{~m}$. Tal fato pode ser atribuído à melhor agregação do solo, resultante dos maiores teores de MOS observados nesses tratamentos, em comparação ao pousio (Tabela 2). A hipótese de que a maior produtividade, nos tratamentos que envolveram plantas de cobertura de inverno, esteja relacionada às melhores condições físicas da superfície do solo, é respaldada pelo fato de a densidade do solo no pousio encontrar-se próxima do limite crítico às plantas sugerido por Reichert et al. (2003), correspondente à faixa de 1,40 a $1,50 \mathrm{Mg} \mathrm{m}^{-3}$, para solos com teores de argila similares ao utilizado no presente estudo. No entanto, as

Tabela 1. Produtividade de grãos de soja e de milho, nas safras 2005/2006 e 2006/2007, em consequência das coberturas de inverno e da profundidade de trabalho do sulco de semeadura ${ }^{(1)}$.

\begin{tabular}{|c|c|c|c|c|c|c|c|c|}
\hline \multirow[t]{2}{*}{ Cobertura de inverno } & \multicolumn{2}{|c|}{$2005 / 2006$} & \multirow[t]{2}{*}{ Média } & \multirow[t]{2}{*}{ CV (\%) } & \multicolumn{2}{|c|}{$2006 / 2007$} & \multirow[t]{2}{*}{ Média } & \multirow[t]{2}{*}{ CV (\%) } \\
\hline & Raso & Profundo & & & Raso & Profundo & & \\
\hline & \multicolumn{8}{|c|}{ Soja } \\
\hline $\mathrm{A}+\mathrm{E} / \mathrm{nabo}^{(2)}$ & 1,82 & 1,93 & $1,87 \mathrm{a}$ & & 3,57 & 3,59 & $3,58 \mathrm{a}$ & \\
\hline Aveia-preta & 1,74 & 1,90 & $1,82 \mathrm{a}$ & 12,1 & 3,46 & 3,66 & $3,56 \mathrm{a}$ & 11,1 \\
\hline Pousio & 1,53 & 1,61 & $1,57 \mathrm{~b}$ & & 3,38 & 3,55 & $3,47 \mathrm{a}$ & \\
\hline Média & $1,70 \mathrm{~A}$ & $1,81 \mathrm{~A}$ & 1,75 & & $3,47 \mathrm{~A}$ & $3,60 \mathrm{~A}$ & 3,54 & \\
\hline $\mathrm{CV}(\%)$ & \multicolumn{2}{|c|}{8,6} & \multicolumn{6}{|c|}{16,5} \\
\hline & & & & & & & & \\
\hline $\mathrm{A}+\mathrm{E} / \mathrm{nabo}$ & 5,69 & 6,32 & $6,00 \mathrm{a}$ & \multirow{4}{*}{10,3} & 4,42 & 3,36 & $3,89 \mathrm{a}$ & \multirow{3}{*}{25,5} \\
\hline Aveia-preta & 6,29 & 6,03 & $6,16 a$ & & 4,20 & 3,96 & $4,08 \mathrm{a}$ & \\
\hline Pousio & 5,13 & 5,49 & $5,31 \mathrm{~b}$ & & 4,43 & 4,51 & $4,47 \mathrm{a}$ & \\
\hline Média & $5,71 \mathrm{~A}$ & $5,94 \mathrm{~A}$ & 5,83 & & $4,35 \mathrm{~A}$ & $3,94 \mathrm{~A}$ & 4,15 & \\
\hline CV (\%) & \multicolumn{2}{|c|}{11,1} & \multicolumn{6}{|c|}{14,7} \\
\hline
\end{tabular}

${ }^{(1)}$ Médias seguidas de letras iguais, maiúsculas nas linhas e minúsculas nas colunas, dentro de cada safra, não diferem pelo teste de Duncan a $5 \%$ de probabilidade. ${ }^{(2)}$ Aveia-preta+ervilhaca (2005) e nabo-forrageiro (2006). 
coberturas de inverno não alteraram significativamente nenhum dos atributos físicos avaliados da camada de $0,12-0,15 \mathrm{~m}$.

A menor cobertura do solo é outro fator que poderia explicar a menor produtividade das culturas no pousio, na safra 2005/2006. No momento da semeadura da soja e do milho, a massa de matéria seca de resíduos, na superfície do solo, era de $11,0,8,6$, e 4,5 $\mathrm{Mg} \mathrm{ha}^{-1}$ nos tratamentos aveia-preta+ervilhaca, aveia-preta e pousio, respectivamente. Entretanto, é provável que a maior cobertura não tenha sido decisiva para o aumento da produtividade de soja e milho nos tratamentos aveia-preta e aveia-preta+ervilhaca, pois os períodos com maior deficiência hídrica (Figura $1 \mathrm{~A}$ ) ocorreram
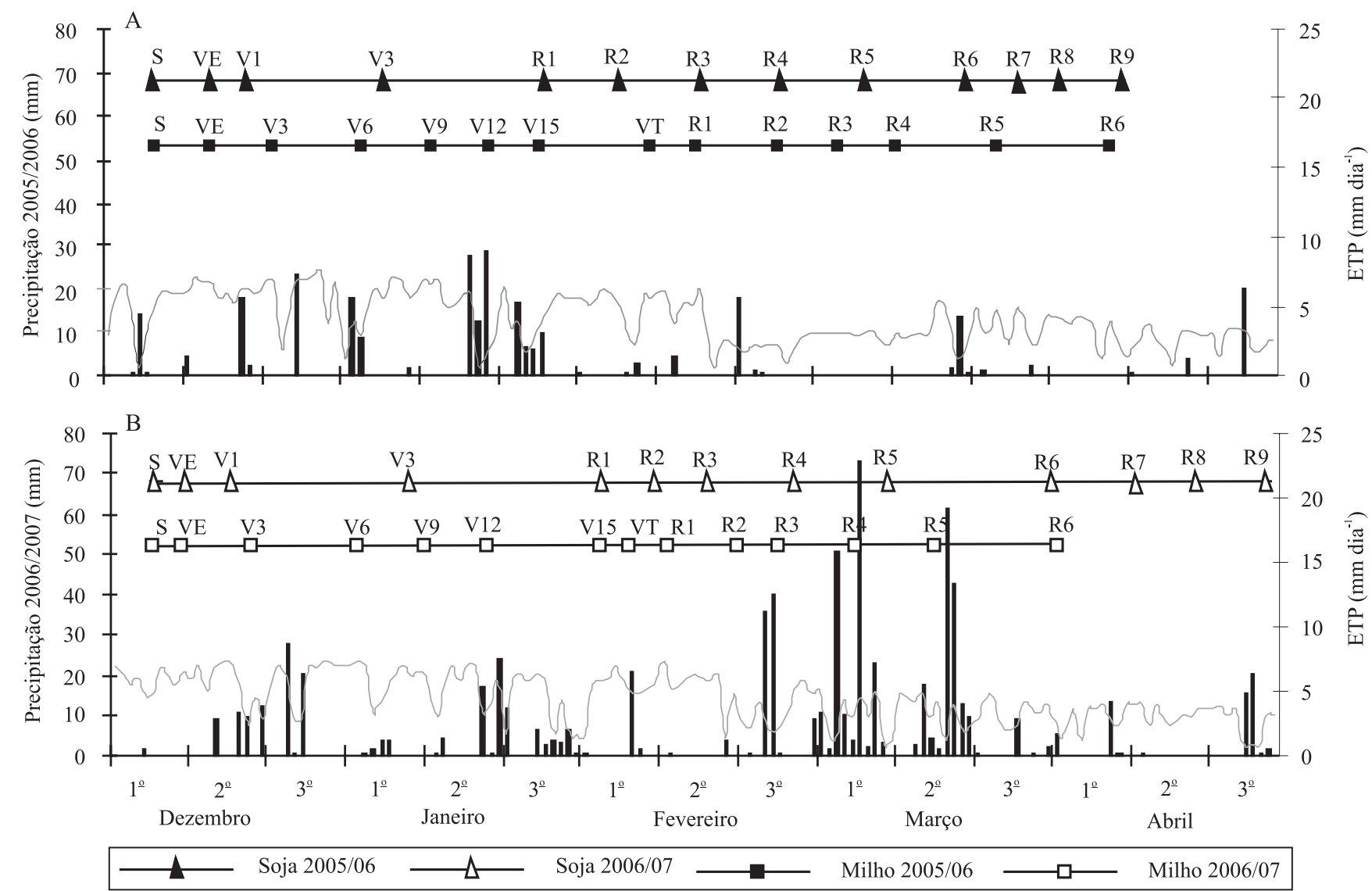

Figura 1. Estádios fenológicos, evapotranspiração potencial (ETP) e volume de chuvas (valores diários), durante o ciclo das culturas de verão nas safras 2005/2006 (A) e 2006/2007 (B). As subdivisões do eixo x referem-se aos decêndios de cada mês.

Tabela 2. Atributos químicos do solo medidos na camada de $0,0-0,12 \mathrm{~m}$, em consequência das coberturas de inverno e do sistema de plantio direto (SPD) contínuo ou escarificado ${ }^{(1)}$.

\begin{tabular}{|c|c|c|c|c|c|c|c|c|c|}
\hline Tratamento & $\mathrm{pH}$ & $\begin{array}{c}\mathrm{MOS} \\
\left(\mathrm{g} \mathrm{kg}^{-1}\right)\end{array}$ & $\begin{array}{c}\mathrm{P} \\
---(\mathrm{m}\end{array}$ & $\begin{array}{c}\mathrm{K} \\
\left.\mathrm{m}^{-3}\right)---\end{array}$ & Al & $\begin{array}{l}\mathrm{Ca} \\
--(\mathrm{cr}\end{array}$ & $\begin{array}{r}\mathrm{Mg} \\
\left.\mathrm{dm}^{-3}\right)\end{array}$ & $\mathrm{T}$ & $\begin{array}{l}\mathrm{V} \\
(\%)\end{array}$ \\
\hline $\mathrm{A}+\mathrm{E} / \mathrm{nabo}^{(2)}$ & 5,3 & $27 a$ & 7,0 & 283 & 0,2 & 3,5 & 1,7 & 10,0 & 60 \\
\hline Aveia-preta & 5,4 & $29 a$ & 6,5 & 236 & 0,1 & 3,8 & 1,8 & 9,6 & 66 \\
\hline Pousio & 5,4 & $25 \mathrm{~b}$ & 7,7 & 257 & 0,1 & 3,9 & 1,8 & 10,6 & 62 \\
\hline Média (SPD contínuo) & 5,4 & 27 & 7,1 & 259 & 0,1 & 3,7 & 1,8 & 10,1 & 63 \\
\hline Média (SPD escarificado) & 5,4 & $26^{*}$ & $6,9^{\mathrm{ns}}$ & $236^{\mathrm{ns}}$ & $0,1^{\mathrm{ns}}$ & $3,9^{\mathrm{ns}}$ & $1,8^{\mathrm{ns}}$ & $9,6^{\mathrm{ns}}$ & $65^{\mathrm{ns}}$ \\
\hline
\end{tabular}

${ }^{(1)}$ Médias seguidas de letras iguais, nas colunas, não diferem entre si pelo teste de Duncan a $5 \%$ de probabilidade. ${ }^{(2)}$ Aveia-preta+ervilhaca (2005) e nabo-forrageiro (2006). ${ }^{n s}$ Não significativo.*Diferenças estatisticamente significativas entre as médias obtidas nas áreas sob plantio direto contínuo e escarificado, pelo teste $\mathrm{t}$ a $5 \%$ de probabilidade. Matéria orgânica do solo (MOS); T, capacidade de troca catiônica a pH 7; V, saturação por bases. Coeficiente de variação da MOS: 10,9\%. 
quando o dossel vegetativo das culturas já cobria a superfície do solo. Nesta condição, a redução das perdas de água por evaporação, em virtude da cobertura do solo, é pouco expressiva (Andrade, 2008).

A resposta diferencial da soja e do milho às coberturas de inverno, quando se compara a safra de 2005/2006 com a de 2006/2007, pode ser justificada pelas diferenças nas condições meteorológicas predominantes durante essas safras. Ao contrário de 2006/2007 (Figura 1 B), em 2005/2006 foram observados vários períodos sem chuvas significativas (Figura 1 A). Um deles ocorreu de 20/2 a 23/4/2006, exatamente durante os estádios reprodutivos da soja e do milho. Sob deficiência hídrica, os efeitos negativos da compactação sobre as plantas são mais acentuados (Beutler et al., 2005), pois a diminuição do conteúdo de água aumenta ainda mais a resistência do solo à penetração das raízes (Cavalieri et al., 2006). Além disso, o armazenamento de água disponível às plantas tende a ser baixo em solos compactados, principalmente em razão da menor capacidade de infiltração (Nicoloso et al., 2008) e condutividade hidráulica não saturada (Silva, 2003).

Respostas positivas da produtividade da soja e do milho ao uso de plantas de cobertura em solos compactados também têm sido obtidas em outros estudos. Beutler (2005) trabalhou neste mesmo experimento e também obteve maior produtividade de milho, em 2002/2003 e 2003/2004, nos tratamentos aveia-preta+ervilhaca e aveia-preta. Nicoloso et al. (2008) concluíram que o consórcio aveia+nabo forrageiro melhorou a qualidade física de um
Latossolo muito argiloso até $0,20 \mathrm{~m}$ de profundidade, o que resultou em maior produtividade da soja, em comparação ao uso da aveia em cultivo solteiro. Genro Junior et al. (2009), também em estudo conduzido sobre um Latossolo muito argiloso, encontraram que o uso da crotalária no sistema de rotação de culturas, embora não tenha diminuído o grau de compactação do solo, aumentou a produtividade da soja.

A profundidade de sulcamento não influenciou significativamente a produtividade da soja e do milho (Tabela 1), independentemente da cobertura de inverno. Isto ocorreu em 2006/2007 e também em 2005/2006, quando períodos de seca foram observados na fase reprodutiva da soja e do milho (Figura 1 A). Beutler (2005) também não obteve resposta positiva da soja e do milho ao aumento da profundidade de atuação das hastes sulcadoras, mesmo sob condições de seca. Conte et al. (2009) concluíram que, na ausência de irrigação, a produtividade de soja foi $180 \mathrm{~kg} \mathrm{ha}^{-1}$ superior quando a haste atuou a $0,10 \mathrm{~m}$, em comparação à atuação a $0,064 \mathrm{~m}$. Os mesmos autores observaram que, na presença de irrigação, a produtividade da soja não foi influenciada pela profundidade de atuação das hastes.

Na safra 2005/2006, a população de plantas, o número de grãos por legume e a massa de mil grãos de soja não variaram significativamente em consequência dos tratamentos (Figura $2 \mathrm{~A}$ ). Os efeitos da profundidade de sulcamento sobre o número de legumes por planta também não foram significativos. Porém, o número de legumes no pousio foi significativamente menor do que nos tratamentos aveia-preta e aveia-preta+ervilhaca. As melhores condições físicas do solo, proporcionadas

Tabela 3. Densidade do solo (DS, $\mathrm{Mg} \mathrm{m}^{-3}$ ), porosidade total $\left(\mathrm{PT}, \mathrm{m}^{3} \mathrm{~m}^{-3}\right)$, macroporosidade (MA, $\mathrm{m}^{3} \mathrm{~m}^{-3}$ ) e microporosidade $\left(\mathrm{MI}, \mathrm{m}^{3} \mathrm{~m}^{-3}\right)$, em consequência das coberturas de inverno e dos sistemas de plantio direto (SPD) contínuo ou escarificado.

\begin{tabular}{|c|c|c|c|c|c|c|c|c|}
\hline \multirow[t]{2}{*}{ Cobertura } & \multicolumn{4}{|c|}{ Camada $0,03-0,06 \mathrm{~m}$} & \multicolumn{4}{|c|}{ Camada $0,12-0,15 \mathrm{~m}$} \\
\hline & DS & PT & MA & MI & DS & PT & MA & MI \\
\hline & \multicolumn{8}{|c|}{ SPD contínuo } \\
\hline $\mathrm{A}+\mathrm{E} / \mathrm{nabo}^{(2)}$ & $1,28 b$ & $0,47 \mathrm{a}$ & $0,19 \mathrm{a}$ & $0,28 \mathrm{a}$ & $1,58 \mathrm{a}$ & $0,37 \mathrm{a}$ & $0,09 \mathrm{a}$ & $0,28 \mathrm{a}$ \\
\hline Aveia-preta & $1,26 b$ & $0,49 \mathrm{a}$ & $0,21 \mathrm{a}$ & $0,28 \mathrm{a}$ & $1,56 \mathrm{a}$ & $0,37 \mathrm{a}$ & $0,10 \mathrm{a}$ & $0,28 \mathrm{a}$ \\
\hline Pousio & $1,42 \mathrm{a}$ & $0,42 b$ & $0,13 b$ & $0,29 \mathrm{a}$ & $1,56 \mathrm{a}$ & $0,37 \mathrm{a}$ & $0,10 \mathrm{a}$ & $0,28 \mathrm{a}$ \\
\hline Média & 1,32 & 0,46 & 0,18 & 0,28 & 1,57 & 0,37 & 0,10 & 0,28 \\
\hline \multirow[t]{2}{*}{ CV $(\%)$} & 7,5 & 9,6 & 17,0 & 10,3 & - & - & - & - \\
\hline & \multicolumn{8}{|c|}{ SPD escarificado } \\
\hline Nabo & $1,12 \mathrm{a}$ & $0,53 \mathrm{a}$ & $0,30 \mathrm{a}$ & $0,23 \mathrm{a}$ & $1,43 \mathrm{a}$ & $0,43 a$ & $0,19 \mathrm{a}$ & $0,24 \mathrm{a}$ \\
\hline Aveia-preta & $1,24 \mathrm{a}$ & $0,50 \mathrm{a}$ & $0,25 \mathrm{a}$ & $0,25 \mathrm{a}$ & $1,35 \mathrm{a}$ & $0,46 \mathrm{a}$ & $0,22 \mathrm{a}$ & $0,24 \mathrm{a}$ \\
\hline Média & $1,18^{*}$ & $0,52 *$ & $0,28^{*}$ & $0,24 *$ & $1,39 *$ & $0,44^{*}$ & $0,20^{*}$ & $0,24 *$ \\
\hline CV (\%) & 8,8 & 11,8 & 17,4 & 10,2 & - & - & - & - \\
\hline
\end{tabular}

${ }^{(1)}$ Médias seguidas de letras iguais, nas colunas, dentro de cada sistema de manejo, não diferem pelo teste de Duncan a $5 \%$ de probabilidade. ${ }^{(2)}$ Aveia-

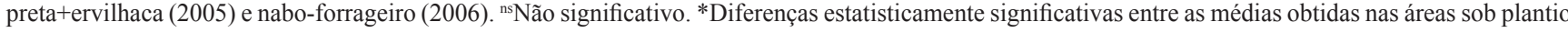
direto contínuo e escarificado, pelo teste t a $5 \%$ de probabilidade. 
pelas plantas de cobertura de inverno, conferiram à soja maior tolerância à falta de chuva durante os estádios reprodutivos da cultura, o que resultou na fixação de um número maior de legumes. Estes dados concordam parcialmente com os obtidos por Thomas \& Costa (1994), que mostraram que o número de legumes e a massa de grãos foram os componentes de produção da soja mais sensíveis à deficiência hídrica. Os componentes de produção e a população de plantas do milho não foram influenciados significativamente pelos tratamentos na safra 2005/2006 (Figura 2 B), o que se contrapõe ao fato de a produtividade ter sido significativamente menor para o pousio (Tabela 1). Entretanto, é provável que a soma de pequenos efeitos das coberturas sobre o número de espigas por hectare $\mathrm{e}$ de grãos por espiga, cujos valores tenderam a ser mais elevados para a aveia-preta e aveia-preta+ervilhaca, tenha resultado nas maiores produtividades obtidas nesses tratamentos.

Os componentes de produção da soja, na safra 2006/2007, não foram significativamente influenciados pelos tratamentos (Figura $2 \mathrm{~A}$ ), o que pode ser atribuído à adequada disponibilidade hídrica durante a fase reprodutiva da cultura (Figura $1 \mathrm{~B}$ ). A população de plantas na colheita foi significativamente menor para o pousio, o que, no entanto, não resultou em redução significativa da produtividade da soja nesse tratamento (Tabela 1). Da mesma forma, os componentes de produção e a população de plantas de milho, na safra 2006/2007, não foram influenciados significativamente pelos tratamentos (Figura $2 \mathrm{~B}$ ).

$\mathrm{Na}$ área escarificada, a produtividade, os componentes da produção e a população de plantas de soja e de milho não variaram significativamente em consequência das coberturas de inverno implantadas logo após a escarificação (Tabela 4). Nicoloso et al. (2008), no entanto, evidenciaram que o uso do consórcio aveia-preta+nabo-forrageiro, logo após a escarificação, em substituição à aveia-preta em cultivo isolado, resultou em aumento de aproximadamente $7,5 \%$ na produtividade da soja. Os autores atribuíram esse fato à estabilização da estrutura criada pela escarificação e a maior cobertura do solo proporcionada pelo consórcio.

A produtividade média da soja, na área escarificada, foi significativamente inferior à observada na área sob SPD (Tabela 4). Este resultado pode ser atribuído à população de plantas, que foi significativamente menor na área escarificada. Os demais componentes de produção da soja não foram significativamente influenciados pela escarificação. Assim, a escarificação prejudicou a germinação e o estabelecimento das plântulas de soja, o que pode ser atribuído à baixa densidade do solo e à alta porosidade total e macroporosidade, observadas na camada superficial da área escarificada (Tabela 2). Nessas condições, o volume de água retido pelo solo é baixo, pois a água tende a drenar rapidamente (Cavalieri et al., 2006). Além disso, em solos excessivamente soltos, a condutividade hidráulica não saturada (Veen et al., 1992) e o contato solo-semente (Raghavan et al., 1979) são diminuídos, o que limita a transmissão de água do solo às sementes. É provável que a baixa densidade do solo e a elevada macroporosidade induzida pela escarificação também tenham prejudicado o desenvolvimento da soja, em razão da menor retenção de água e condutividade hidráulica não saturada, bem como do menor contato solo-raiz(Veen etal., 1992).Essas condições, associadas à ocorrência de um período de quinze dias sem chuvas significativas, no subperíodo reprodutivo da soja (Figura $1 \mathrm{~B}$ ), impediram que a cultura compensasse a menor população de plantas, principalmente por meio da fixação de um maior número de legumes.

De modo similar ao observado para a soja, a escarificação reduziu significativamente a produtividade do milho em relação ao SPD contínuo (Tabela 4). Essa redução resultou do menor número de plantas e de espigas por $\mathrm{m}^{2}$ na área escarificada, em relação ao observado sob SPD contínuo, já que os demais componentes de produção não foram significativamente influenciados pela escarificação. Tal fato pode ser associado, mais uma vez, aos valores excessivamente baixos de densidade do solo e altos de macroporosidade na área escarificada (Tabela 2), o que, provavelmente, reduziu a disponibilidade de água.

Os efeitos da escarificação esporádica no SPD sobre a produtividade de soja e de milho têm sido extensivamente estudados em solos argilosos, e os resultados são variáveis. Secco et al. (2009), em trabalho conduzido sobre dois Latossolos, concluíram que a produtividade da soja não respondeu à escarificação, porém a produtividade do milho foi maior nas áreas escarificadas. Efeitos positivos da escarificação sobre a produtividade do milho também foram observados por Secco \& Reinert (1997). Secco et al. (2004) concluíram que a produtividade de soja foi aumentada pela 
escarificação apenas em relação àárea sob SPD contínuo com maior grau de compactação, submetida a cinco passagens de um rolo compactador. Klein \& Camara (2007), em trabalho realizado sobre um Latossolo muito argiloso, concluíram que a produtividade da soja não diferiu entre o SPD contínuo e o SPD escarificado. Ao comparar a escarificação mecânica com a biológica
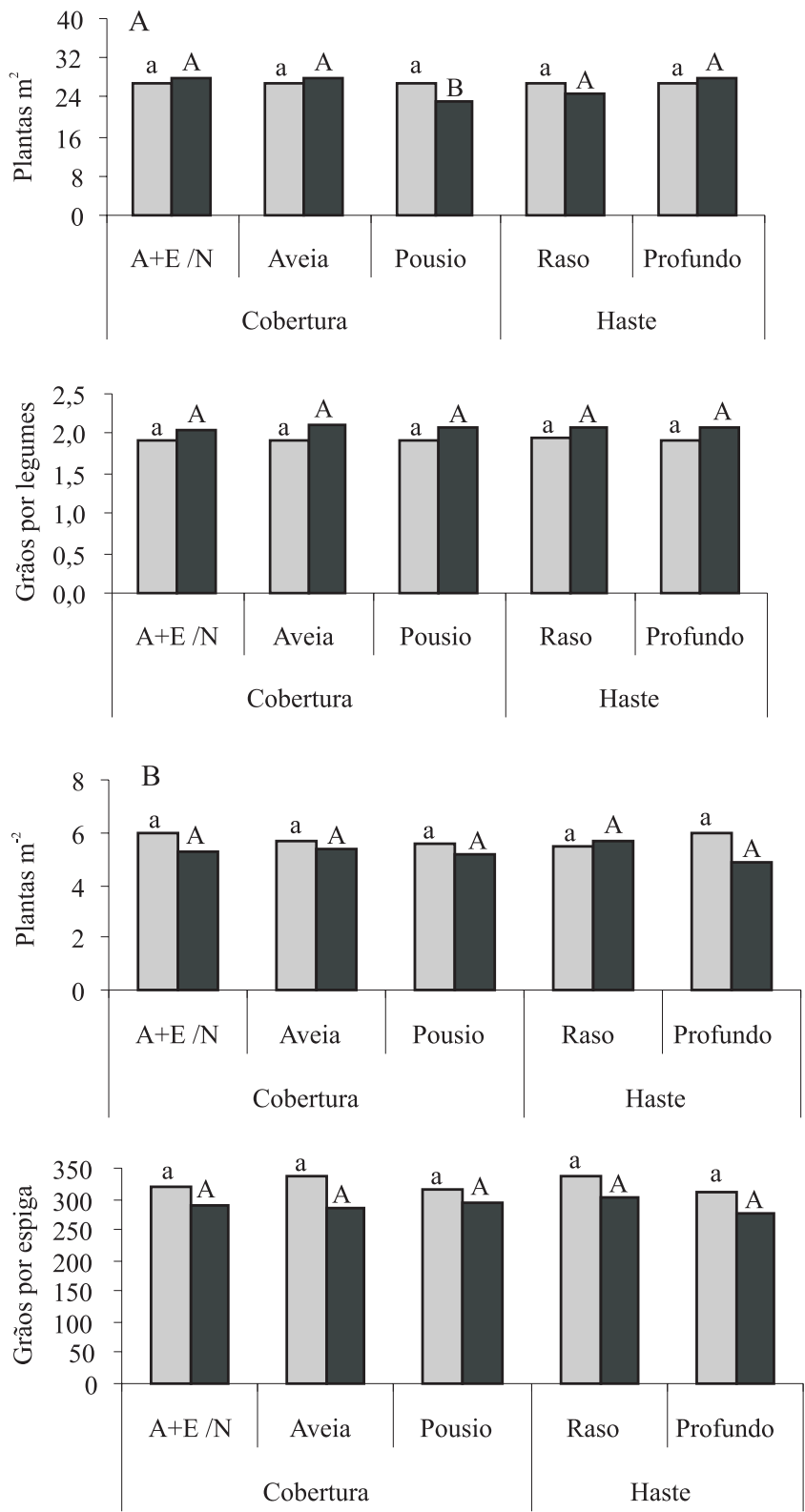

(nabo-forrageiro+aveia-preta), em um Latossolo muito argiloso, Nicoloso et al. (2008) concluíram que as duas práticas beneficiaram a qualidade física do solo e aumentaram a produtividade da soja de modo similar.

Em contrapartida, a resposta da soja e do milho à escarificação no SPD, em solos de textura média a arenosa, tem sido pouco estudada. Lima et al.
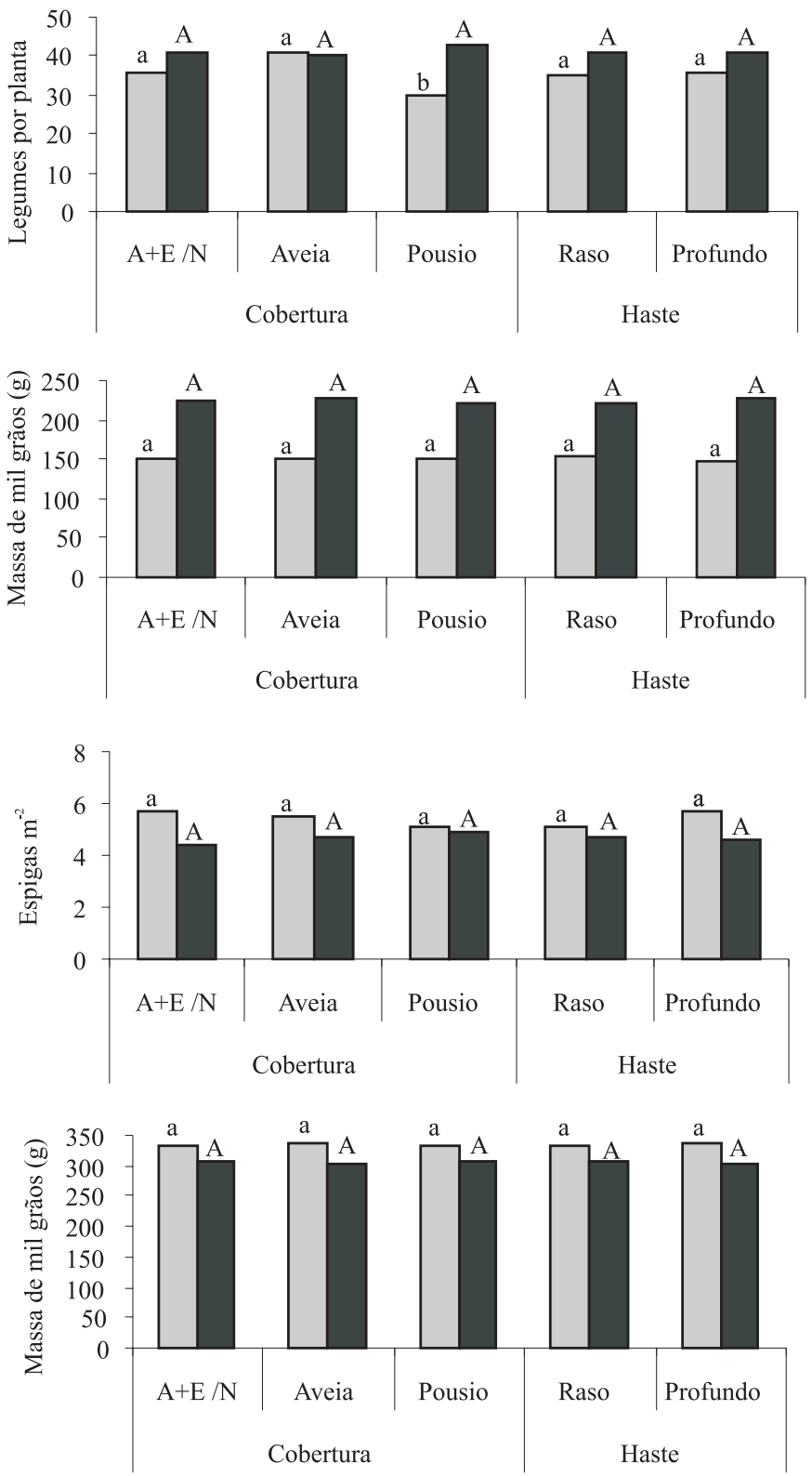

$\square 2005 / 2006 \quad \square 2006 / 2007$

Figura 2. Componentes de produção da soja (A) e do milho (B), nas safras 2005/2006 e 2006/2007, em consequência das coberturas de inverno e da profundidade de trabalho da haste sulcadora. A+E/N: aveia-preta+ervilhaca (2005) e nabo-forrageiro (2006). Dentro de um mesmo fator de variação, médias identificadas por letras iguais, minúsculas na safra 2005/2006 e maiúsculas na safra 2006/2007, não diferem entre si pelo teste de Duncan, a 5\% de probabilidade. 
Tabela 4. Produtividade e componentes da produção de soja e de milho - população, número de legumes ou espigas por planta (NLE), número de grãos por legume ou espiga (NG) e massa de mil grãos -, nas áreas em sistema de plantio direto (SPD) escarificado e contínuo ${ }^{(1)}$.

\begin{tabular}{|c|c|c|c|c|c|}
\hline $\begin{array}{l}\text { Cobertura } \\
\text { de inverno }\end{array}$ & $\begin{array}{l}\text { População } \\
\left(\text { plantas } \mathrm{m}^{-2}\right)\end{array}$ & NLE & NG & $\begin{array}{l}\text { Massa de mil } \\
\text { grãos (g) }\end{array}$ & $\begin{array}{l}\text { Produtividade } \\
\left(\mathrm{Mg} \mathrm{ha}^{-1}\right)\end{array}$ \\
\hline & & & Soja & & \\
\hline Nabo-forrageiro & $19 \mathrm{a}$ & $37 \mathrm{a}$ & $2,18 \mathrm{a}$ & $216 \mathrm{a}$ & $3,00 \mathrm{a}$ \\
\hline Aveia-preta & $25 \mathrm{a}$ & $36 \mathrm{a}$ & $2,05 \mathrm{a}$ & $232 \mathrm{a}$ & $3,28 \mathrm{a}$ \\
\hline Média (SPD escarificado) & 22 & 36 & 2,11 & 224 & 3,14 \\
\hline CV (\%) & 10,3 & 11,3 & 2,3 & 5,4 & 16,7 \\
\hline \multirow[t]{2}{*}{ Média (SPD contínuo) } & $27 *$ & $40^{\mathrm{ns}}$ & $2,08^{\mathrm{ns}}$ & $224^{\mathrm{ns}}$ & $3,47^{*}$ \\
\hline & & & Milho & & \\
\hline Nabo-forrageiro & $4,4 a$ & $4,0 \mathrm{a}$ & $243 b$ & $307 \mathrm{a}$ & $3,03 \mathrm{a}$ \\
\hline Aveia-preta & $4,7 \mathrm{a}$ & $4,0 \mathrm{a}$ & $297 \mathrm{a}$ & $301 \mathrm{a}$ & $3,50 \mathrm{a}$ \\
\hline Média (SPD escarificado) & 4,5 & 4,0 & 270 & 304 & 3,26 \\
\hline CV (\%) & 9,3 & 10,4 & 11,4 & 2,6 & 13,4 \\
\hline Média (SPD contínuo) & $5,3^{\mathrm{ns}}$ & $4,6^{*}$ & $308^{\text {ns }}$ & $308^{\mathrm{ns}}$ & $4,31^{*}$ \\
\hline
\end{tabular}

${ }^{(1)}$ Médias seguidas de letras iguais, nas colunas, não diferem entre si pelo teste de Duncan, a $5 \%$ de probabilidade. ${ }^{\text {ns}}$ Não significativo; $*$ Diferenças estatisticamente significativas entre as médias obtidas nas áreas sob plantio direto contínuo e escarificado, pelo teste t a 5\% de probabilidade.

(2006) encontraram que a escarificação no SPD, num Argissolo arenoso, não aumentou a produtividade da soja, mesmo quando esse tratamento foi comparado ao SPD compactado por quatro passadas de uma máquina com massa de $10 \mathrm{Mg}$. Collares et al. (2006), em pesquisa conduzida sobre Argissolo arenoso, concluíram que, embora a escarificação tenha favorecido o desenvolvimento radicular do feijoeiro, a produtividade foi até $12 \%$ inferior ao SPD contínuo.

\section{Conclusão}

O emprego de plantas de cobertura no inverno é uma alternativa viável para atenuação dos efeitos de compactação do solo, em áreas sob sistema de plantio direto, considerando-se a produtividade do milho e da soja, em comparação à escarificação e ao uso de maiores profundidades de atuação das hastes sulcadoras da semeadora.

\section{Referências}

ANDRADE, J.G. Perdas de água por evaporação de um solo cultivado com milho nos sistemas de plantio direto e convencional. 2008. 93p. Dissertação (Mestrado) - Universidade Federal de Santa Maria, Santa Maria.

BEUTLER, A.N.; CENTURION, J.F.; ROQUE, C.G.; FERRAZ, M.V. Densidade relativa ótima de Latossolos Vermelhos para a produtividade de soja. Revista Brasileira de Ciência do Solo, v.29, p.843-849, 2005.

BEUTLER, J.F. Parâmetros de solo e máquinas na semeadura direta de milho e soja em duas coberturas de solo sobre campo natural. 2005. 107p. Tese (Doutorado) - Universidade Federal do Rio Grande Sul, Porto Alegre.
CAVALIERI, K.M.V.; TORMENA, C.A.; VIDIGAL FILHO, P.S.; GONÇALVES, A.C.A.; COSTA, A.C.S. da. Efeitos de sistemas de preparo nas propriedades físicas de um Latossolo Vermelho distrófico. Revista Brasileira de Ciência do Solo, v.30, p.137-147, 2006.

CLAESSEN, M.E.C. Manual de métodos e análise de solo. 2.ed. rev. atual. Rio de Janeiro: Embrapa-CNPS, 1997. 212p. (Embrapa-CNPS. Documentos, 1).

COLLARES, G.L.; REINERT, D.J.; REICHERT, J.M.; KAISER, D.R. Qualidade física do solo na produtividade da cultura do feijoeiro num Argissolo. Pesquisa Agropecuária Brasileira, v.41, p.1663-1674, 2006.

CONTE, O.; LEVIEN, R.; TREIN, C.R.; XAVIER, A.A.P.; DEBIASI, H. Demanda de tração, mobilização de solo na linha de semeadura e rendimento da soja, em plantio direto. Pesquisa Agropecuária Brasileira, v.44, p.1254-1261, 2009.

GENRO JUNIOR, S.A.; REINERT, D.J.; REICHERT, J.M.; ALBUQUERQUE, J.A. Atributos físicos de um Latossolo Vermelho e produtividade de culturas cultivadas em sucessão e rotação. Ciência Rural, v.39, p.65-73, 2009.

KLEIN, V.A.; CAMARA, R.K. Rendimento da soja e intervalo hídrico ótimo em Latossolo Vermelho sob plantio direto escarificado. Revista Brasileira de Ciência do Solo, v.31, p.221-227, 2007.

LIMA, C.L.R. de; REINERT, D.J.; REICHERT, J.M.; SUZUKI, L.E.A.S.; GUBIANI, P.I. Qualidade físico-hídrica e rendimento de soja (Glycine max L.) e feijão (Phaseolus vulgaris L.) de um Argissolo Vermelho distrófico sob diferentes sistemas de manejo. Ciência Rural, v.36, p.1172-1178, 2006.

NICOLOSO, R. da S.; AMADO, T.J.C.; SCHNEIDER, S.; LANZANOVA, M.E.; GIRARDELLO, V.C.; BRAGAGNOLO, J. Eficiência da escarificação mecânica e biológica na melhoria dos atributos físicos de um Latossolo muito argiloso e no incremento do rendimento de soja. Revista Brasileira de Ciência do Solo, v.32, p.1723-1734, 2008. 
OADES, J.M. The role of biology in the formation, stabilization and degradation of soil structure. Geoderma, v.56, p.377-400, 1993.

RAGHAVAN, G.S.V.; MCKYES, E.; TAYLOR, F.; RICHARD, P.; DOUGLAS, E.; NEGI, S.; WATSON, A. Corn yield affected by wheel compaction in a dry year. Canadian Agricultural Engineering, v.21, p.27-29, 1979.

REICHERT, J.M.; KAISER, D.R.; REINERT, D.J.; RIQUELME, U.F.B. Variação temporal de propriedades físicas do solo e crescimento radicular de feijoeiro em quatro sistemas de manejo. Pesquisa Agropecuária Brasileira, v.44, p.310-319, 2009.

REICHERT, J.M.; REINERT, D.J.; BRAIDA, J.A. Manejo, qualidade do solo e sustentabilidade: condições físicas do solo agrícola. In: CONGRESSO BRASILEIRO DE CIÊNCIA DO SOLO, 29., 2003, Ribeirão Preto. Anais. Ribeirão Preto: Sociedade Brasileira de Ciência do Solo, 2003. p.1-17.

SECCO, D.; REINERT, D.J. Efeitos imediato e residual de escarificadores em Latossolo Vermelho-Escuro sob plantio direto. Engenharia Agrícola, v.16, p.52-61, 1997.

SECCO, D.; REINERT, D.J.; REICHERT, J.M.; ROS, C.O. da. Produtividade da soja e propriedades físicas de um Latossolo submetido a sistemas de manejo e compactação. Revista Brasileira de Ciência do Solo, v.28, p.797-804, 2004.

SECCO, D.; REINERT, D.J.; REICHERT, J.M.; SILVA, V.R. da. Atributos físicos e rendimento de grãos de trigo, soja e milho em dois Latossolos compactados e escarificados. Ciência Rural, v.39, p.58-64, 2009.

SILVA, R.H. da; ROSOLEM, C.A. Crescimento radicular de soja em razão da sucessão de cultivos e da compactação do solo. Pesquisa Agropecuária Brasileira, v.37, p.855-860, 2002.

SILVA, V.R. Propriedades físicas e hídricas em solos sob diferentes estados de compactação. 2003. 171p. Tese (Doutorado) - Universidade Federal de Santa Maria, Santa Maria.

SOCIEDADE BRASILEIRA DE CIÊNCIA DO SOLO. Núcleo Regional Sul. Comissão de Química e Fertilidade do Solo, RS/ SC. Manual de adubação e de calagem para os Estados do Rio Grande do Sul e Santa Catarina. 10.ed. Porto Alegre: SBCS, 2004. 400p.

TEDESCO, M.J.; GIANELLO, C.; BISSANI, C.A.; BOHNEN, H.; VOLKWEISS, S.J. Análise de solo, plantas e outros materiais. 2.ed. rev. ampl. Porto Alegre: UFRGS, 1995. 174p. (UFRGS. Boletim técnico, 5).

THOMAS, A.L.; COSTA, J.A. Influência do deficit hídrico sobre o desenvolvimento e rendimento da soja. Pesquisa Agropecuária Brasileira, v.29, p.1389-1396, 1994.

VEEN, B.W.; NOORDWIJK, M. van; WILLIGEN, P. de; BOONE, F.R.; KOOISTRA, M.J. Root-soil contact of maize, as measured by a thin-section technique. Plant and Soil, v.139, p.131-138, 1992.

XU, X.; NIEBER, J.L.; GUPTA, S.C. Compaction effect on the gas diffusion coefficient in soils. Soil Science Society of America Journal, v.56, p.1743-1750, 1992.

Recebido em 22 de dezembro de 2009 e aprovado em 31 de maio de 2010 